\title{
Cardiovascular magnetic resonance evidence of myocardial fibrosis and its clinical significance in adolescent and adult patients with Ebstein's anomaly
}

Dan Yang ${ }^{1+}$, Xiao Li ${ }^{2 \dagger}$, Jia-Yu Sun ${ }^{3}$, Wei Cheng ${ }^{3}$, Andreas Greiser ${ }^{4}$, Tian-Jing Zhang ${ }^{5}$, Hong Liu', Ke Wan ${ }^{1}$, Yong Luo', Qi An², Yiu-Cho Chung ${ }^{6}$, Yuchi Han ${ }^{7}$ and Yu-Cheng Chen ${ }^{1 *}$ (D)

\begin{abstract}
Background: Myocardial fibrosis is a common pathophysiological process that is related to ventricular remodeling in congenital heart disease. However, the presence, characteristics, and clinical significance of myocardial fibrosis in Ebstein's anomaly have not been fully investigated. This study aimed to evaluate myocardial fibrosis using cardiovascular magnetic resonance (CMR) late gadolinium enhancement (LGE) and T1 mapping techniques, and to explore the significance of myocardial fibrosis in adolescent and adult patients with Ebstein's anomaly.

Methods: Forty-four consecutive patients with unrepaired Ebstein's anomaly (34.0 \pm 16.2 years; 18 males), and an equal number of age- and gender-matched controls, were included. A comprehensive CMR protocol consisted of cine, LGE, and T1 mapping by modified Look-Locker inversion recovery (MOLLI) sequences were performed. Ventricular functional parameters, native T1, extracellular volume (ECV), and LGE were analyzed. Associations between myocardial fibrosis and disease severity, ventricular function, and NYHA classification were analyzed.

Results: LGE was found in 10 (22.7\%) patients. Typical LGE in Ebstein's anomaly was located in the endocardium of the septum within the right ventricle (RV). The LV ECV of Ebstein's anomaly were significantly higher than those of the controls ( $30.0 \pm 3.8 \%$ vs. $25.3 \pm 2.3 \%, P<0.001$ ). An increased ECV was found to be independent of the existence of LGE. Positive LGE or higher ECV ( $\geq 30 \%$ ) was associated with larger fRV volume, aRV volume, increased disease severity, and worse NYHA functional class. In addition, ECV was significantly correlated with the LV ejection fraction $(P<0.001)$.

Conclusions: Both focal and diffuse myocardial fibrosis were observed in adolescent and adult patients with Ebstein's anomaly. Increased diffuse fibrosis is associated with worse LV function, increased Ebstein's severity, and worse clinical status.
\end{abstract}

Keywords: Ebstein's anomaly, Cardiovascular magnetic resonance imaging, Extracellular volume, Late gadolinium enhancement, Left ventricular function, Myocardial fibrosis

\footnotetext{
* Correspondence: chenyucheng2003@126.com

${ }^{\dagger}$ Dan Yang and Xiao Li contributed equally to this work.

'Department of Cardiology, West China Hospital, Sichuan University,

Chengdu 610041, Sichuan Province, China

Full list of author information is available at the end of the article
}

(c) The Author(s). 2018 Open Access This article is distributed under the terms of the Creative Commons Attribution 4.0 International License (http://creativecommons.org/licenses/by/4.0/), which permits unrestricted use, distribution, and reproduction in any medium, provided you give appropriate credit to the original author(s) and the source, provide a link to the Creative Commons license, and indicate if changes were made. The Creative Commons Public Domain Dedication waiver (http://creativecommons.org/publicdomain/zero/1.0/) applies to the data made available in this article, unless otherwise stated. 


\section{Background}

Ebstein's anomaly is a rare congenital heart disease. It is considered a right ventricular (RV) myopathy with failure of delamination of the tricuspid leaflets. Ebstein's anomaly is associated with considerable tricuspid regurgitation and the formation of an atrialized right ventricle (aRV) [1-4]. Compromised RV function, in varying degrees, is frequently found in Ebstein's anomaly, and it is believed to be the major cause of heart failure $[2,3,5,6]$.

Compared with the tricuspid valve and RV abnormalities, the left ventricle (LV) of Ebstein's anomaly is less studied. LV dysfunction was found in 7-50\% patients with Ebstein's anomaly and was associated with worse prognosis after surgery [7-10]. The mechanism of LV dysfunction in Ebstein's anomaly is yet to be explored. Myocardial fibrosis was found in the left heart of decedents with Ebstein's anomaly [11, 12]. Limited by the available techniques, to date, it has been difficult to explore the relationship between myocardial fibrosis and ventricular dysfunction in vivo.

Cardiovascular magnetic resonance (CMR) is a powerful non-invasive imaging modality to evaluate myocardial fibrosis. Late gadolinium enhancement (LGE) is an established CMR technique that provides accurate quantitation of myocardial replacement fibrosis. Recent advances in CMR native $\mathrm{T} 1$ mapping have provided us with a groundbreaking tool for quantification of diffuse myocardial fibrosis. The extracellular volume fraction (ECV) calculated from pre and post contrast T1 mapping images showed a strong correlation with collagen volume fraction histologically obtained from endomyocardial biopsies [13, 14]. Myocardial LGE is strongly related to myocardial viability, ventricular function, and adverse prognosis in patients with ischemic heart disease, dilated cardiomyopathy, hypertrophic cardiomyopathy, and cardiac amyloidosis [15-18]. In congenital heart disease, the existence of LGE located in the RV outflow tract is associated with the occurrence of ventricular tachycardia in patients with repaired Tetralogy of Fallot [19]. T1 mapping also revealed diffuse fibrosis in repaired Tetralogy of Fallot and pulmonary hypertension $[20,21]$. With the availability of these techniques, we are now able to study myocardial fibrosis and its significance in patients with Ebstein's anomaly. Therefore, in the present study, we employed LGE and T1 mapping techniques to quantify focal and diffuse myocardial fibrosis in patients with Ebstein's anomaly, and to investigate their correlations with the severity of Ebstein's anomaly, ventricular function, and clinical status.

\section{Methods}

\section{Study population}

Consecutive patients with unrepaired Ebstein's anomaly referred to our institution for clinical evaluation gave their consent and were enrolled into a registry since June 2013. All patients received a comprehensive evaluation including a detailed medical history, physical examination, oxygen saturation test, routine blood examination (including serum creatine), electrocardiography, echocardiography, and CMR imaging. Patients in our registry database from June 2013 to Oct 2016 were reviewed and patients with complete data sets and those older than ten years of age were included in the study. Exclusion criteria were as follows: 1) Contraindications to contrast-enhanced CMR; 2) other coexisting cardiomyopathy, such as hypertrophic, restrictive, or infiltrative cardiomyopathy; 3) a history of known coronary heart disease or myocarditis; 4) other complex congenital cardiac anomalies (e.g., congenitally corrected transposition with Ebstein's anomaly); 5) CMR image quality was too poor to analyze due to significant arrhythmia or difficulty with breath-holding. Patients were grouped into Carpentier's classification of types A to D, based on the mobility of the tricuspid leaflet and the RV shape and contractility on echocardiography [22].

An equal number of age- and gender-matched subjects were included as controls. Healthy adults with no documented cardiovascular diseases or other major illnesses, and with normal echocardiograms, were recruited as volunteers. Subjects younger than 18 years old were selected for CMR examination to screen for myocarditis. Subjects were included as controls if all clinical data, routine blood work, electrocardiography, echocardiography, and CMR examination excluded cardiovascular disease. All patients and controls (or their parents if a subject was younger than 18 years old) gave written informed consent for their data to be included in this study.

\section{CMR data acquisition}

CMR was performed on a $3 \mathrm{~T}$ scanner (Magnetom Tim Trio, Siemens Healthineers, Erlangen, Germany) with using a 32-channel phased-array cardiac coil. All images were acquired with electrocardiogram (ECG)-gated breath-hold technique. All patients were scanned according to the standard imaging protocol for Ebstein's anomaly [23]. The protocol consisted of stacks of balanced steady-state free-precession (bSSFP) cine images acquired in the three long-axis (two-, three-, and four-chamber) views, consecutive short-axis views covering the LV from base to apex (TR/TE $3.4 \mathrm{~ms} / 1.3 \mathrm{~ms}$, flip angle $50^{\circ}$, FOV $300 \times 340 \mathrm{~mm}$, matrix size $256 \times 144$, slice thickness $8 \mathrm{~mm}$ ), and consecutive axial cine bSSFP images covering the whole heart extending from the pulmonary bifurcation to just below the diaphragm. LGE images were acquired using a T1-weighted inversion recovery turboflash sequence 10 to $20 \mathrm{~min}$ after bolus contrast injection (Gadopentetate dimeglumine, $0.15 \mathrm{mmol} / \mathrm{kg}$, Bayer HealthCare Pharmaceuticals, Wayne, New Jersey, USA) in 
the same planes. T1 measurements were performed by using a Modified Look-Locker Inversion Recovery sequence (MOLLI) at the LV basal-, mid- and apicallevels, with the following parameters: non-selective inversion pulse, bSSFP single shot readout with $35^{\circ}$ flip angle, minimum inversion time $110 \mathrm{~ms}$, inversion time increment $80 \mathrm{~ms}$, TR/TE of 2.9/1.12 ms, FOV of $360 \times$ $272 \mathrm{~mm}$, matrix size of $256 \times 144$, Voxel size of $2.1 \times 1.4 \times$ $8 \mathrm{~mm}^{3}$ and slice thickness of $8 \mathrm{~mm}$. The inversion time for each patient was chosen at the time of scanning from the TI scout images, with three heartbeats for recovery between each experiment. Native T1 measurements were acquired before injection of gadolinium, with an imaging scheme of 5(3)3), and post contrast T1 measurements were repeated in the same short-axis slices 10-15 min after the administration of gadolinium with a scheme of 4(1)3(1)2. The hematocrit was tested within $24 \mathrm{~h}$ of CMR scanning for ECV calculation.

\section{CMR functional analysis}

CMR images were analyzed using a commercially available software package (QMass ${ }^{\oplus}$ 7.6, Medis, Leiden, The Netherlands). Biventricular volume and function were obtained by tracing epicardial and endocardial contours manually on both end-diastolic and end-systolic phases. The LV volume, function, and mass were measured based on the consecutive short-axis slices. RV volume and function were derived from the axial views, as described in previous studies [1, 24]. All volumetric parameters were indexed to body surface area (BSA). The tracing method for the chambers was similar to the previous description by Fratz et al. [2, 25]. A line along the tricuspid leaflets was used to segment the aRV and the functional right ventricle (fRV). The fRV is defined as the part of the RV distal to the tricuspid leaflets. The border demarcating the $\mathrm{aRV}$ and morphological right atrium (RA) is defined as the curved line along the presumed tricuspid valve annulus, from the free wall attachment of the anterior tricuspid valve leaflet to the point of presumed septal leaflet attachment [25]. The trabeculae and papillary muscles were included in the ventricular blood pool.

\section{Quantification of myocardial fibrosis}

LGE images were visually assessed on phase sensitive inversion recovery (PSIR) images at the short- and long-axis views by two experienced CMR imagers (YCC, and JYS, both with > 300 cases/year experience in CMR). The myocardial $\mathrm{T} 1$ calculation was based on the LV short axis MOLLI images with motion correction. The endocardial and epicardial contours were traced manually on the pre-contrast T1-mapping images and post-contrast T1-mapping images. The T1 curve was fitted automatically using the software (QMass ${ }^{\oplus}$ 7.6, Medis), and the mean myocardial T1 was obtained. At the same time, the blood T1 was obtained by drawing an ROI in the blood pool within the LV cavity in the pre-contrast and post-contrast T1-mapping images, respectively. The ECV was calculated as [26]:

$$
\mathrm{ECV}=(1 \text {-hematocrit }) \frac{\left(\frac{1}{\text { T1 myo post }}-\frac{1}{T 1 \text { myo pre }}\right)}{\left(\frac{1}{T 1 \text { blood post }}-\frac{1}{T 1 \text { blood pre }}\right)}
$$

\section{Severity of Ebstein's anomaly}

In our study, the severity index (SI) and total right/left-volume index (Total R/L-volume index) were utilized to quantify the severity of EA. SI, described by Fratz et al., was calculated using the area of the RA, aRV, fRV, left atrium (LA), and LV traced in end-diastole on the four-chamber view $[1,2,25]$. The total R/L-volume index was defined by Hösch et al. as the ratio of the total volume of the right heart and left heart, measured in the end-diastole on the axial views [27]. The equations for the two indices are shown as:

$$
\mathrm{SI}=\text { area of }\left(\frac{R A+a R V}{f R V+L A+L V}\right)
$$

Total R/L-Volume Index $=$ volume of $\left(\frac{R A+a R V+f R V}{L A+L V .}\right)$

\section{Statistical analysis}

Statistical analysis was performed using SPSS 17.0 (SPSS Inc., International Business Machines, Armonk, New York, USA). Numerical data in normal distribution were expressed as the mean \pm standard deviation (SD), or else were expressed as the median with the interquartile range. Continuous data were compared using a paired t-test. Categorical data were expressed as frequencies and compared using a $\chi^{2}$ test or the Fisher's exact test as appropriate. Correlations between variables were analyzed by using Pearson's or Spearman correlation analyses. Univariable factors related to the ECV at $p<0.1$ were included in the multivariate stepwise regression analysis. Statistical significance was defined as $P<0.05$.

\section{Results \\ Demographic, clinical characteristics and basic CMR functional data}

Ultimately, the Ebstein's anomaly registry database comprised data from seventy-eight patients. Patients were excluded from the study because of: age $<10$ years $(n=12)$, no contrast was used $(n=2)$, poor image quality caused by due to persistent atrial fibrillation or unable to breath hold $(n=10)$, and T1 mapping not performed $(n=10)$. The remaining 44 patients were included in the study. The mean age of the patients was $34.0 \pm 16.2$ years (range 10-60) years. Seven patients were between 10 and 
18 years. Age, gender and BMI were well balanced between patients and the healthy control groups. Among the 44 patients, 29 (65.9\%) had an atrial septal defect or patent foramen ovale. Tricuspid regurgitation was graded as severe in 32 (72.7\%) and moderate in $12(27.3 \%)$ patients (Table 1$)$.

\section{Left and right ventricular volume, function and remodeling}

LV end diastolic volume (EDV) index was reduced in Ebstein's anomaly patients $(68.3 \pm 16.8$ vs. $79.0 \pm 17.1 \mathrm{ml}$, $P=0.007$ ) (Table 2). LV ejection fraction (EF) and LV mass index in Ebstein's anomaly was decreased (52.8 \pm $7.6 \%$, vs. $60.6 \pm 3.7 \%, P<0.001$; and $39.2 \pm 9.1 \mathrm{~g} / \mathrm{m} 2$ vs. $45.2 \pm 11.1 \mathrm{~g} / \mathrm{m} 2, P=0.004$, respectively). LVEF was reduced $(<50 \%)$ in $34.1 \%(n=15)$ of the Ebstein's anomaly patients. The LV mass to volume ratio was not significantly different from the control group. Both total and fRV EDV indices and RV end systolic volume (ESV) index were significantly increased compared with those

Table 1 Characteristics of patients and controls

\begin{tabular}{|c|c|c|c|}
\hline & $\begin{array}{l}\text { Ebstein's anomaly } \\
(N=44)\end{array}$ & $\begin{array}{l}\text { Healthy Subjects } \\
(N=44)\end{array}$ & $P$ value \\
\hline Age, yrs & $34.0 \pm 16.2$ & $33.3 \pm 16.1$ & 0.923 \\
\hline $10 \leq$ age $\leq 18$, yrs & $7(15.9)$ & $7(15.9)$ & 1.000 \\
\hline Male (n, \%) & 18(40.9) & $18(40.9)$ & 1.000 \\
\hline BSA, $\mathrm{m}^{2}$ & $1.5 \pm 0.2$ & $1.6 \pm 0.2$ & 0.468 \\
\hline $\mathrm{BMI}, \mathrm{kg} / \mathrm{m}^{2}$ & $21.8 \pm 4.8$ & $21.7 \pm 3.5$ & 0.932 \\
\hline Heart rate, bpm & $83.3 \pm 12.7$ & $73.6 \pm 11.6$ & $<0.001$ \\
\hline $\mathrm{SO}_{2}$ at rest, $\%$ & $96.6 \pm 2.6$ & $99.0 \pm 1.0$ & $<0.001$ \\
\hline Hematocrit, \% & $42.5 \pm 4.9$ & $44.1 \pm 5.2$ & 0.071 \\
\hline ASD/PFO (n, \%) & $29(65.9)$ & 0 & - \\
\hline W-P-W (n, \%) & $6(13.6)$ & 0 & - \\
\hline $\begin{array}{l}\text { Tricuspid regurgitation } \\
\text { severity }(n, \%)\end{array}$ & & & - \\
\hline Moderate & $12(27.3)$ & 0 & - \\
\hline Severe & $32(72.7)$ & 0 & - \\
\hline \multicolumn{4}{|l|}{ Carpentier's classification } \\
\hline Type A & $18(40.9)$ & - & - \\
\hline Type B & 17 (38.6) & - & - \\
\hline Type C & $8(18.2)$ & - & - \\
\hline Type D & $1(2.3)$ & - & - \\
\hline \multicolumn{4}{|c|}{ NYHA functional classification (n, \%) } \\
\hline । & $10(22.7)$ & - & - \\
\hline$\|$ & $29(65.9)$ & - & - \\
\hline III & $5(11.4)$ & - & - \\
\hline
\end{tabular}

Abbreviations: $B S A$ body surface area; $B M I$ body mass index; $A S D$ atrial septal defect; $P F O$ patent foramen ovale; $W-P$-W Wolff-Parkinson-White; NYHA New York Heart Association
Table 2 Cardiovascular magnetic resonance parameters

\begin{tabular}{|c|c|c|c|}
\hline & $\begin{array}{l}\text { Ebstein's anomaly } \\
(N=44)\end{array}$ & $\begin{array}{l}\text { Healthy subjects } \\
(N=44)\end{array}$ & $P$ value \\
\hline LV EDV index, $\mathrm{ml} / \mathrm{m}^{2}$ & $68.3 \pm 16.8$ & $79.0 \pm 17.1$ & 0.007 \\
\hline LV ESV index, $\mathrm{ml} / \mathrm{m}^{2}$ & $32.5[12.1]$ & $31.3[7.9]$ & 0.577 \\
\hline LV EF, \% & $52.8 \pm 7.6$ & $60.6 \pm 3.7$ & $<0.001$ \\
\hline LV mass index, $\mathrm{g} / \mathrm{m}^{2}$ & $39.2 \pm 9.1$ & $45.2 \pm 11.1$ & 0.004 \\
\hline LV mass/volume & $0.58 \pm 0.15$ & $0.60 \pm 0.10$ & 0.892 \\
\hline fRV EDV index, $\mathrm{ml} / \mathrm{m}^{2}$ & $138.9[66.6]$ & $73.6[18.6]$ & $<0.001$ \\
\hline fRV ESV index, $\mathrm{ml} / \mathrm{m}^{2}$ & $77.3[41.9]$ & $34.4[10.4]$ & $<0.001$ \\
\hline fRV EF, \% & $43.7 \pm 11.5$ & $53.6 \pm 6.3$ & $<0.001$ \\
\hline Total R/L-Volume-Index & $4.3 \pm 2.5$ & - & - \\
\hline SI & $1.0 \pm 0.4$ & - & - \\
\hline \multicolumn{4}{|l|}{ LV Native T1, ms } \\
\hline Global & $1224.8 \pm 86.6$ & $1198.8 \pm 45.4$ & 0.084 \\
\hline Septal & $1244.4 \pm 97.1$ & $1218.0 \pm 44.3$ & 0.124 \\
\hline Free wall & $1209.5 \pm 103.8$ & $1199.9 \pm 71.2$ & 0.630 \\
\hline \multicolumn{4}{|l|}{ LV ECV, \% } \\
\hline Global & $30.0 \pm 3.8$ & $25.3 \pm 2.3$ & $<0.001$ \\
\hline Septal & $31.2 \pm 5.0$ & $25.4 \pm 2.3$ & $<0.001$ \\
\hline Free wall & $28.9 \pm 4.5$ & $25.4 \pm 2.7$ & $<0.001$ \\
\hline LGE positive, n (\%) & $10(22.7)$ & - & - \\
\hline
\end{tabular}

Abbreviations: $L V$ left ventricle; $E D V$ end diastolic volume; $E S V$ end systolic volume; $E F$ ejection fraction; $f R V$ functional right ventricle; Total R/L-VolumeIndex, total right/left volume index; SI severity index; ECV extracellular volume; LGE late gadolinium enhancement

of the controls. The fRV EF in Ebstein's anomaly was significantly reduced $(P<0.001)$.

\section{Prevalence, characteristics, and clinical relevance of LGE} LGE was seen in 10 out of 44 (22.7\%) Ebstein's anomaly patients. The typical LGE pattern was linear or patchy localized within the RV subendocardium of the basal septum (Fig. 1). Only one Ebstein's anomaly patient showed focal transmural LGE in the basal septum and posteromedial papillary muscle (shown in Fig. 1). No remarkable LGE was seen in the LV free wall. In Ebstein's anomaly patients with LGE, the indexed fRV EDV and ESV were significantly larger than those patients without LGE (both $P$ value $<0.01$ ). The fRV EF was lower in patients with LGE than without. The aRV volume was also significantly larger in the LGE-positive group than the LGE-negative group. Ebstein's anomaly severity evaluated by the total $\mathrm{R} / \mathrm{L}$-volume index was more severe in patients with LGE than without LGE, while the SI was not significantly different between these two groups. Patients with LGE also had a higher NYHA functional class and lower oxygen saturation at rest than patients without LGE $(P=0.011$ and 0.042 , respectively). The LV 

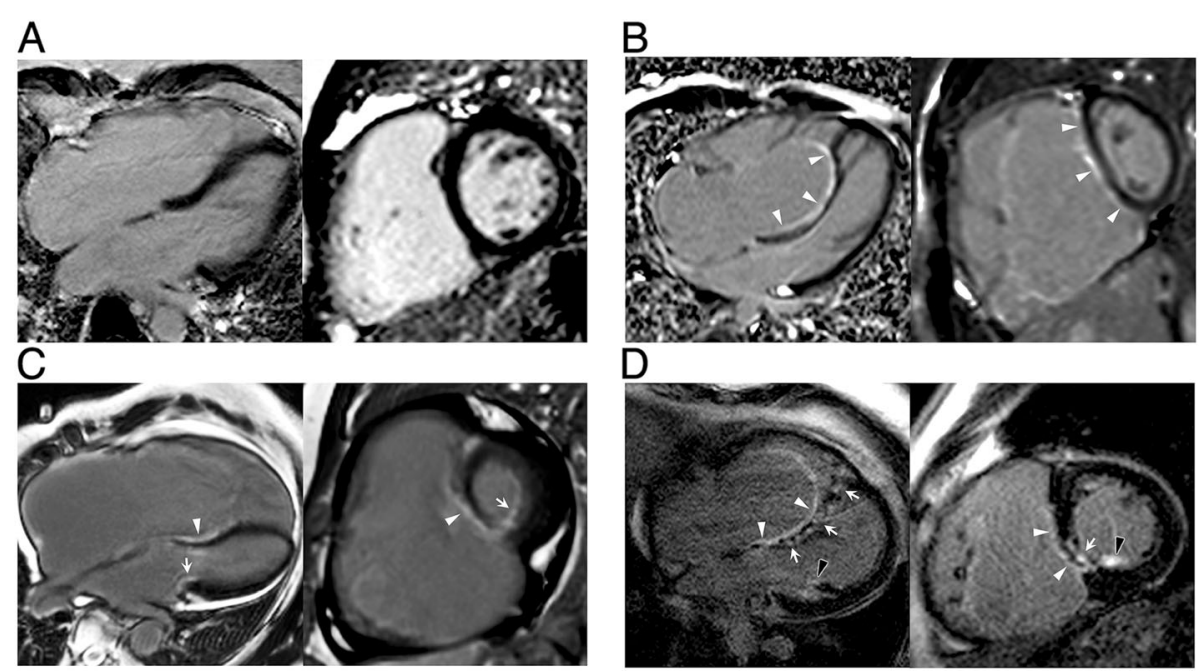

Fig. 1 Representative images of late gadolinium enhancement (LGE) in patients with Ebstein's anomaly. a. Patient without LGE. b. Endocardial LGE along atrialized right ventricular (aRV) wall (white arrow heads). c. LGE in both left ventricular (LV) (arrows) and aRV (white arrow heads) endothelium. d. Endocardial LGE in aRV (white arrow heads), with sporadic and patchy myocardial LGE in interventricular septum (arrows). LGE was also noted in the posterior papillary muscle (black arrow heads). LGE, late gadolinium enhancement; aRV, atrialized right ventricle; LV, left ventricle

volume and the LV EF were lower in patients with LGE; however, the difference was not significant. All data are shown in Table 3.

\section{Average native T1, myocardial ECV, and regional changes}

The native $\mathrm{T} 1$ was higher but not statistically significant in patients with Ebstein's anomaly. The average myocardial ECV was significantly increased in patients with Ebstein's anomaly $(P<0.001)$. The septal ECV was higher than that of the free ventricular wall in Ebstein's anomaly patients and free wall ECV was significantly higher than that of the controls $(\mathrm{P}<0.001)$. Twenty (45.5\%) patients had an ECV higher than $30 \%$, which is above the upper limits of normal. Except for one a-60-year old, all subjects in the control group had an ECV less than $30 \%$. In patients with a higher ECV, the Ebstein's anomaly severity index, NYHA class and tricuspid regurgitation were significantly worse than in patients with a normal ECV. The LVEF was much lower in Ebstein's anomaly patients with a higher ECV than those with a normal ECV (Table 4). The hematocrit was observed to be lower in patients with higher ECV, while no linear correlation was present between the hematocrit and the ECV of the LV myocardium.

To explore the relationship between LGE and the ECV, we compared ECV between Ebstein's anomaly patients with and without LGE. Figure 2 shows that the global ECV was higher in Ebstein's anomaly patients with LGE than patients without LGE $(P=0.038)$. It is important to recognize that the ECV in patients without LGE was still significantly higher than that of the controls. The same trend was found (Fig. 2) when the ECV was analyzed separately in the septum versus the free wall. Individual global ECV values in the EA and control groups are shown in Fig. 3.

\section{Correlation between the ECV and clinical characteristics,} ventricular function and disease severity

Among all variables, the ECV of the LV myocardium was significantly correlated with NYHA class, tricuspid regurgitation severity, the LV ESV index, the LV EF, the fRV EDV index, the fRV ESV index, and the fRV EF (Table 5). Moreover, we found that the ECV of the LV myocardium had a moderate correlation with the Ebstein's anomaly severity (severity index: $r=0.392, P=0.009$; Total $\mathrm{R} / \mathrm{L}$-volume index: $r=0.612, \quad P<0.001)$. Multivariate correlation analysis showed that ECV was independently correlated with LVEF.

\section{Discussion}

To the best of our knowledge, this is the first study to investigate diffuse myocardial fibrosis in Ebstein's anomaly using CMR. The main findings are: (1) both focal myocardial fibrosis and diffuse myocardial fibrosis were detected by CMR in Ebstein's anomaly patients. (2) Diffuse myocardial fibrosis was more common than focal myocardial fibrosis in Ebstein's anomaly, and both were associated with the severity of Ebstein's anomaly. (3) Diffuse myocardial fibrosis demonstrated by $\mathrm{T} 1$ mapping was closely associated with LV dysfunction.

Ebstein's anomaly has a wide spectrum of clinical manifestations, from early death in neonates to mild symptoms surviving into adulthood [28]. Heart failure 
Table 3 Comparison between Ebstein anomaly patient groups with and without LGE

\begin{tabular}{|c|c|c|c|}
\hline & $\begin{array}{l}\text { LGE positive } \\
(N=10)\end{array}$ & $\begin{array}{l}\text { LGE negative } \\
(N=34)\end{array}$ & $P$ \\
\hline Age, yrs & $40.4 \pm 16.1$ & $31.6 \pm 15.8$ & 0.131 \\
\hline Male (n, \%) & $6(60)$ & $12(35.3)$ & 0.273 \\
\hline Heart rate, bpm & $78.1 \pm 7.8$ & $84.7 \pm 13.4$ & 0.147 \\
\hline $\mathrm{BMl}, \mathrm{kg} / \mathrm{m}^{2}$ & $22.8 \pm 4.8$ & $21.4 \pm 4.8$ & 0.428 \\
\hline NYHA classification & $2.3 \pm 0.5$ & $1.8 \pm 0.5$ & 0.011 \\
\hline $\mathrm{SO}_{2}$ at rest, $\%$ & $95.1 \pm 2.6$ & $97.1 \pm 2.5$ & 0.042 \\
\hline Severe TR $(n, \%)$ & $8(80.0)$ & $24(70.6)$ & 0.557 \\
\hline ASD/PFO (n, \%) & $7(70.0)$ & $22(64.7)$ & 1.000 \\
\hline W-P-W (n, \%) & $1(10.0)$ & $5(14.7)$ & 0.950 \\
\hline QRS width, ms & $114.2 \pm 19.0$ & $113.5 \pm 15.2$ & 0.910 \\
\hline LV EDV index, $\mathrm{ml} / \mathrm{m}^{2}$ & $62.5[12.6]$ & $71.1[21.2]$ & 0.233 \\
\hline LV ESV index, $\mathrm{ml} / \mathrm{m}^{2}$ & $30.6[5.6]$ & $33.7[15.3]$ & 0.537 \\
\hline LV EF, \% & $49.2 \pm 10.5$ & $53.7 \pm 6.7$ & 0.106 \\
\hline fRV EDV index, $\mathrm{ml} / \mathrm{m}^{2}$ & $194.5[87.7]$ & $127.4[57.4]$ & 0.007 \\
\hline fRV ESV index, $\mathrm{ml} / \mathrm{m}^{2}$ & $123.6[64.4]$ & $67.4[28.7]$ & $<0.001$ \\
\hline fRV EF, \% & $40.1 \pm 12.7$ & $45.0 \pm 11.1$ & 0.251 \\
\hline aRV EDV index, $\mathrm{ml} / \mathrm{m}^{2}$ & $107.6 \pm 76.16$ & $62.4 \pm 35.9$ & 0.011 \\
\hline Total R/L-Volume-Index & $6.9 \pm 3.4$ & $3.5 \pm 1.7$ & 0.011 \\
\hline SI & $1.1 \pm 0.4$ & $0.9 \pm 0.4$ & 0.195 \\
\hline
\end{tabular}

Abbreviations: $L G E$ late gadolinium enhancement; $B M I$ body mass index; NYHA New York Heart Association; TR tricuspid regurgitation; ASD atrial septal defect; $P F O$ patent foramen ovale; $W-P-W$ Wolff-Parkinson-White; $L V$ left ventricle; $E D V$ end diastolic volume; $E S V$ end systolic volume; $E F$ ejection fraction; fRV functional right ventricle; $a R V$ atrialized right ventricle; Total R/L-Volume-Index, total right/left volume index; S/ severity index

is one of the common symptoms in adult Ebstein's anomaly, which is a result of biventricular dysfunction [7, 29-31]. LV dysfunction was observed in previous studies and is considered a high-risk factor for mortality after surgery and long-term survival [10, 32]. In Ebstein's anomaly, LV dysfunction was considered as a consequence of compression caused by a dilated RV and abnormal septal motion [9]. A recent study further corroborated LV dysfunction in Ebstein's anomaly with LV regional irregularity and the effect of RV longitudinal contraction. However, these mechanisms do not adequately explain why in some patients, postoperative LV dysfunction persisted and was associated with suboptimal survival [10].

The finding of LV myocardial fibrosis in Ebstein's anomaly provides another perspective on this question. In early studies, myocardial fibrosis was found in ex-vivo hearts of patients with Ebstein's anomaly, in which histopathological examination demonstrated myocardial fibrosis existed in the fetus and neonate. Interstitial fibrosis was more common in both the RV LV and sporadic replacement myocardial fibrosis also existed [33-35]. Whether or not
Table 4 Comparison between Ebstein anomaly patient groups with different ECV

\begin{tabular}{|c|c|c|c|}
\hline & $\begin{array}{l}E C V \geq 30 \% \\
(N=20)\end{array}$ & $\begin{array}{l}\mathrm{ECV}<30 \% \\
(N=24)\end{array}$ & $P$ \\
\hline Age, yrs & $34.9 \pm 15.7$ & $32.6 \pm 16.7$ & 0.648 \\
\hline Male $(n, \%)$ & $6(30.0)$ & $12(50.0)$ & 0.227 \\
\hline Heart rate, bpm & $83.6 \pm 11.0$ & $83.0 \pm 14.0$ & 0.852 \\
\hline $\mathrm{BMI}, \mathrm{kg} / \mathrm{m}^{2}$ & $21.2 \pm 4.3$ & $22.2 \pm 5.2$ & 0.488 \\
\hline NYHA classification & $2.1 \pm 0.4$ & $1.7 \pm 0.6$ & 0.020 \\
\hline $\mathrm{SO}_{2}$ at rest, $\%$ & $96.2 \pm 2.6$ & $97.0 \pm 2.8$ & 0.411 \\
\hline Severe tricuspid regurgitation (n, \%) & $18(90.0)$ & $14(58.3)$ & 0.019 \\
\hline ASD/PFO (n, \%) & $15(75.0)$ & $14(58.3)$ & 0.342 \\
\hline W-P-W (n, \%) & $3(15.0)$ & $3(12.5)$ & 0.329 \\
\hline Hematocrit, \% & $40.0 \pm 4.3$ & $44.7 \pm 4.5$ & 0.001 \\
\hline QRS width, ms & $113.2 \pm 17.3$ & $114.1 \pm 14.9$ & 0.862 \\
\hline LV EDV index, $\mathrm{ml} / \mathrm{m}^{2}$ & $67.7[26.0]$ & $70.3[13.2]$ & 0.671 \\
\hline LV ESV index, $\mathrm{ml} / \mathrm{m}^{2}$ & $35.6[18.7]$ & $31.0[7.1]$ & 0.259 \\
\hline LV EF, \% & $48.0 \pm 8.3$ & $56.7 \pm 4.7$ & $<0.001$ \\
\hline fRV EDV index, $\mathrm{ml} / \mathrm{m}^{2}$ & $168.1[77.7]$ & $121.4[56.8]$ & 0.026 \\
\hline fRV ESV index, $\mathrm{ml} / \mathrm{m}^{2}$ & $100.0[53.7]$ & $63.6[29.3]$ & 0.011 \\
\hline fRV EF, \% & $38.4 \pm 12.3$ & $46.2 \pm 11.0$ & 0.117 \\
\hline aRV EDV index, $\mathrm{ml} / \mathrm{m}^{2}$ & $89.0 \pm 58.4$ & $59.1 \pm 39.7$ & 0.051 \\
\hline Total R/L-Volume-Index & $5.8 \pm 2.8$ & $3.1 \pm 1.4$ & $<0.001$ \\
\hline $\mathrm{SI}$ & $1.13 \pm 0.4$ & $0.86 \pm 0.4$ & 0.036 \\
\hline
\end{tabular}

Abbreviations: $E C V$ extracellular volume; $B M I$ body mass index; NYHA New York Heart Association; ASD atrial septal defect; PFO patent foramen ovale; $W-P-W$ Wolff-Parkinson-White; $L V$ left ventricle; $E D V$ end diastolic volume; $E S V$ end systolic volume; $E F$ ejection fraction; $f R V$ functional right ventricle; $a R V$ atrialized right ventricle; Total R/L-Volume-Index, total right/left volume index; SI severity index

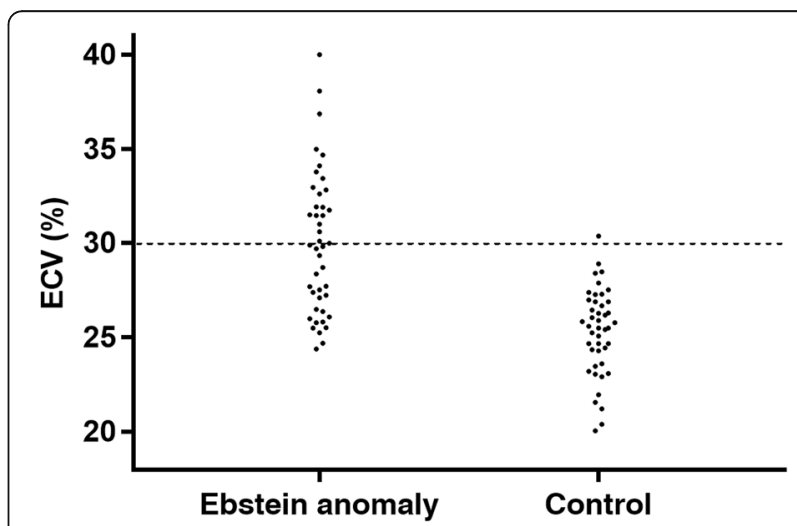

Fig. 2 Distribution of global extracellular volume (ECV) in patients with Ebstein's anomaly and healthy control subjects. ECV, extracellular volume 


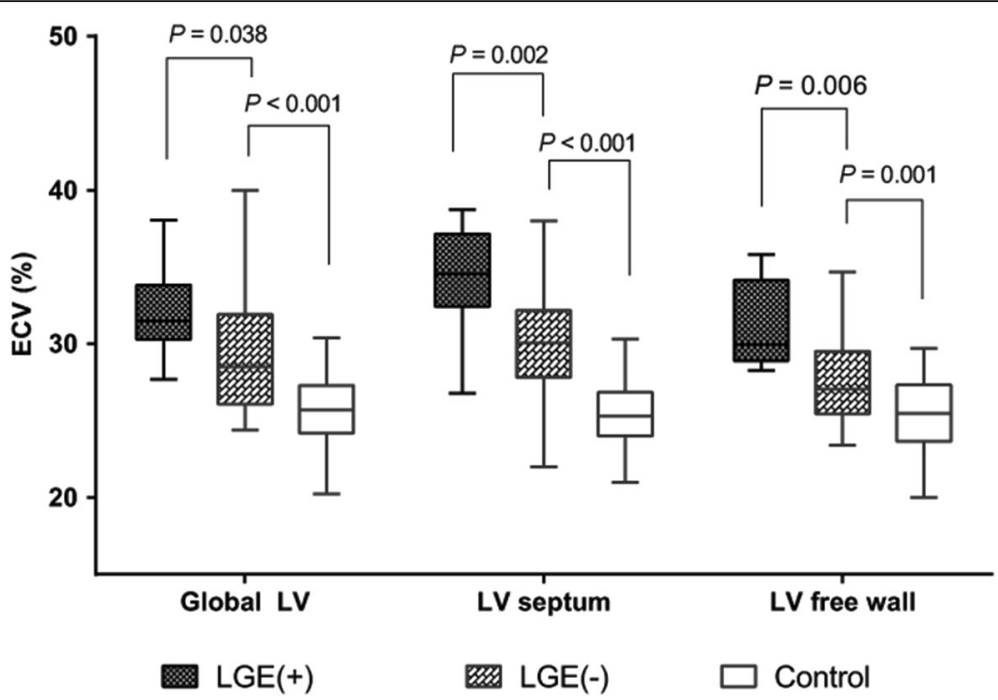

Fig. 3 Box plots display the discrepancy of ECV among LGE (+), LGE (-) and healthy control group in global, septal wall and LV free wall. ECV, extracellular volume; LGE, late gadolinium enhancement; LV, left ventricle

Table 5 Univariate and multivariate linear regression of factors associated with ECV

\begin{tabular}{|c|c|c|c|c|}
\hline & \multicolumn{2}{|c|}{ Univariate } & \multicolumn{2}{|l|}{ Multivariate } \\
\hline & $r$ & $P$ & B & $P$ \\
\hline Age & -0.043 & 0.782 & & \\
\hline Gender & -0.058 & 0.707 & & \\
\hline NYHA classification & -0.407 & 0.006 & 0.082 & 0.518 \\
\hline $\mathrm{SO}_{2}$ & -0.195 & 0.093 & & \\
\hline Hematocrit, \% & -0.282 & 0.163 & & \\
\hline Tricuspid regurgitation severity & -0.326 & 0.031 & 0.022 & 0.858 \\
\hline ASD/PFO & 0.145 & 0.346 & & \\
\hline W-P-W, \% & -0.021 & 0.893 & & \\
\hline LV EDV index & 0.132 & 0.392 & & \\
\hline LV ESV index & 0.415 & 0.005 & & \\
\hline LVEF & -0.694 & $<0.001$ & -0.330 & $<0.001$ \\
\hline fRV EDV index & 0.407 & 0.006 & 0.123 & 0.326 \\
\hline fRV ESV index & 0.470 & 0.001 & & \\
\hline fRV EF & -0.307 & 0.043 & -0.054 & 0.658 \\
\hline aRV EDV index & 0.274 & 0.072 & & \\
\hline Total R/L-volume index & 0.612 & $<0.001$ & 0.210 & 0.215 \\
\hline SI & 0.392 & 0.009 & 0.061 & 0.470 \\
\hline
\end{tabular}

Abbreviations: ECV extracellular volume; NYHA New York Heart Association; SI severity index; $A S D$ atrial septal defect; $P F O$ patent foramen ovale; $W-P-W$ Wolff-Parkinson-White; $L V$ left ventricle; $E D V$ end diastolic volume; ESV end systolic volume; $E F$ ejection fraction; $f R V$ functional right ventricle; $a R V$ atrialized right ventricle; Total R/L-Volume-Index, total right/left volume index; SI severity index myocardial fibrosis is an intrinsic property or an acquired characteristic secondary to abnormal hemodynamics in Ebstein's anomaly is still controversial [33]. Only one study showed that the heart in adult Ebstein's anomaly patients had interstitial myocardial fibrosis in both ventricles, while very mild myocardial fibrosis was shown in neonates. Due to the limited specimen from autopsies, it is very difficult to confirm detailed mechanisms and characteristics of myocardial fibrosis in Ebstein's anomaly.

In the present study, both LGE and elevated ECV were observed in Ebstein's anomaly patients. The typical LGE pattern found in this study was mostly localized in the endocardium of the aRV septum. This finding was in accordance with a previous case report [36]. In one case, mid myocardial wall LGE (non-ischemic pattern) was observed in the basal to mid septum. In contrast to LGE, which was only found in a minority of Ebstein's anomaly patients, interstitial fibrosis, as evidenced by a mean LV ECV elevation greater than the upper two SD limits of the control ECV, was demonstrated in more than $45 \%$ of patients. This finding was in line with previous autopsy results [33].

Both LGE and elevated ECV were related to the severity of Ebstein's anomaly and ventricular dysfunction in this group of Ebstein's anomaly patients. This finding emphasizes the importance of focal and diffuse myocardial fibrosis in ventricular remodeling in Ebstein's anomaly. LV remodeling was related to Ebstein's anomaly severity, which demonstrated a close RV-LV interaction [37, 38]. Furthermore, the relationship between the severity of Ebstein's anomaly and LV ECV also suggested the impact of an abnormal RV on LV myocardial remodeling [10]. The inverse relationship between an elevated LV ECV and LV function found in Ebstein's anomaly patients was observed in dilated 
cardiomyopathy [39]. LV dysfunction in Ebstein's anomaly has been considered to result from chronic hemodynamic under-filling of the LV and is possibly related to myocardial cell degeneration. The present study provided evidence for diffuse myocardial fibrosis, which could be an important contributor to biventricular dysfunction in Ebstein's anomaly.

LV dysfunction is a high-risk factor in Ebstein's anomaly and is associated with higher mortality after surgery [40]. Preservation and reversal of LV dysfunction in Ebstein's anomaly could be a potential treatment target. In patients with mild or asymptomatic Ebstein's anomaly, indications for surgery include deterioration of ventricular function, persistent enlargement of the heart, exercise intolerance, and arrhythmia [41]. The value of CMR detection of myocardial fibrosis in Ebstein's anomaly in decision-making for surgical treatment requires further study. In a study on aortic valve stenosis, an elevated ECV persisted for at least six months after aortic valve replacement surgery [42]. Earlier intervention might be necessary to reverse myocardial remodeling.

In our study, ECV was also associated with clinical and imaging-based ventricular function. Thus, ECV is a potential imaging marker for risk stratification in Ebstein's anomaly patients. Future CMR evaluation for Ebstein's anomaly should not only include volume and function analysis, but also consider myocardial tissue characterization using LGE and ECV.

\section{Limitations}

There are several limitations to our study. First, the present study consisted of both adolescent and adult patients, and does not represent the entire Ebstein's anomaly spectrum. Second, the ECV of the RV myocardium was not quantified because the RV free wall was too thin in Ebstein's anomaly for accurate assessment. Third, the cross-sectional study design limited the ability to determine the impact of myocardial fibrosis on the long-term prognosis of Ebstein's anomaly. Our study indicated that further longitudinal observation is needed to clarify the impact of myocardial fibrosis and remodeling in Ebstein's anomaly patients.

\section{Conclusions}

Focal and diffuse myocardial fibrosis assessed by LGE and ECV were observed in Ebstein's anomaly patients. The elevated fibrosis was associated with worse LV function, greater disease severity, and reduced clinical status in Ebstein's anomaly patients. LGE or ECV may serve as imaging markers for the severity of Ebstein's anomaly. Further studies are needed to assess the prognostic significance of these findings.

\section{Abbreviations}

aRV: Atrialized right ventricle; BSA: Body surface area; bSSFP: Balanced steady state free precession; CMR: Cardiovascular magnetic resonance;

ECG: Electrocardiogram; ECV: Extracellular volume; EDV: End-diastolic volume; EF: Ejection fraction; ESV: End-systolic volume; fRV: Functional right ventricle; LA: Left atrium/left atrial; LGE: Late gadolinium enhancement; LV: Left ventricle/left ventricular; MOLLI: Modified Look-Locker inversion recovery; PSIR: Phase sensitive inversion recover; RA: Right atrium/right atrial; ROI: Region of interest; RV: Right ventricle/right ventricular; SI: Severity index; Total R/L-volume index: Total right/left volume index

\section{Acknowledgements \\ Not applicable.}

\section{Author contributions}

D Yang, X Li and YC Chen: contributed substantially to the conception and design of the study, recruitment of subjects, analysis, interpretation and drafting the manuscript; JY Sun and W Chen, contributed substantially to CMR data acquisition and analyses, interpretation and generation of T1- and colored T1-maps; Andreas Greiser and TJ Zhang contributed to interpretation and generation of T1 mapping; Y Luo,H Liu and K Wan contributed to data acquisition and recruitment of subjects; $Y$ Han contributed to study design and critically revised the manuscript; YC Chen participated in the design and coordination of the study and critically revised the manuscript. All authors read and approved the final manuscript.

\section{Funding}

This work was supported by two grants from the National Natural Science Foundation, People's Republic of China (No. 81271531 and No. 81571638).

Availability of data and materials

All data generated or analysis during this study are included in this published article.

\section{Ethics approval and consent to participate}

The study was approved by the Clinical Trial and Biological Ethics Committee of Sichuan University, and all patients provided written informed consent. The study of the healthy subjects was approved by the Clinical Trial and Biological Ethics Committee of Sichuan University, and all healthy subjects provided written informed consent.

\section{Consent for publication}

Written informed consent was obtained from the patient (or guardian) for publication of their individual details and accompanying images in this manuscript. The consent form is held by the authors/the authors' institution and is available for review by the Editor-in-Chief.

\section{Competing interests}

Dr. Chung is the investigator of Shenzhen Institutes of Advanced Technology. Andreas Greiser and Tian-Jing Zhang are the investigators on a cooperative Research and Development Agreement with Siemens. The remaining authors declare that they have no competing interests.

\section{Publisher's note}

Springer Nature remains neutral with regard to jurisdictional claims in published maps and institutional affiliations

\footnotetext{
Author details

'Department of Cardiology, West China Hospital, Sichuan University, Chengdu 610041, Sichuan Province, China. ${ }^{2}$ Department of Cardiovascular Surgery/Pediatric Heart Center, West China Hospital, Sichuan University, Chengdu 610041, Sichuan Province, China. ${ }^{3}$ Department of Radiology, West China Hospital, Sichuan University, Chengdu 610041, Sichuan Province, China. ${ }^{4}$ Siemens Healthcare GmbH, Erlangen, Germany. ${ }^{5}$ Northeast Asia MR Collaboration, Siemens Healthcare, Beijing, China. ${ }^{6}$ Paul C. Lauterbur Research Centre for Biomedical Imaging, Shenzhen Key Laboratory for MRI, Shenzhen Institutes of Advanced Technology, Chinese Academy of Sciences, Shenzhen, Guangdong, China. ${ }^{7}$ Department of Medicine (Cardiovascular Division), University of Pennsylvania, Philadelphia, PA, USA.
} 
Received: 13 June 2017 Accepted: 5 September 2018 Published online: 27 September 2018

\section{References}

1. Tobler D, Yalonetsky S, Crean AM, Granton JT, Burchill L, Silversides CK, et al. Right heart characteristics and exercise parameters in adults with Ebstein anomaly: new perspectives from cardiac magnetic resonance imaging studies. Int J Cardiol. 2013;165:146-50.

2. Fratz S, Janello C, Muller D, Seligmann M, Meierhofer C, Schuster T, et al. The functional right ventricle and tricuspid regurgitation in Ebstein's anomaly. Int J Cardiol. 2013;167:258-61.

3. Attenhofer Jost CH. H.M.Connolly, W.D.Edwards, D H, Carole a.Warnes, G.K. Danielson. Ebstein's anomaly - review of a multifaceted congenital cardiac condition. Swiss Med Wkly. 2005;165:269-81.

4. Dearani JA, Mora BN, Nelson TJ, Haile DT, O'Leary PW. Ebstein anomaly review: what's now, what's next? Expert Rev Cardiovasc Ther. 2015;13:1101-9.

5. Lee CM, Sheehan FH, Bouzas B, Chen SS, Gatzoulis MA, Kilner PJ. The shape and function of the right ventricle in Ebstein's anomaly. Int J Cardiol. 2013; 167:704-10

6. Li X, Wang SM, Schreiber C, Cheng W, Lin K, Sun JY, et al. More than valve repair: effect of cone reconstruction on right ventricular geometry and function in patients with Ebstein anomaly. Int J Cardiol. 2016;206: 131-7.

7. Goleski PJ, Sheehan FH, Chen SS, Kilner PJ, Gatzoulis MA. The shape and function of the left ventricle in Ebstein's anomaly. Int J Cardiol. 2014;171:404-12.

8. Attenhofer Jost CH, Connolly HM, O'Leary PW, Warnes CA, Tajik AJ, Seward JB. Left heart lesions in patients with Ebstein anomaly. Mayo Clin Proc. 2005; 80:361-8.

9. Benson LN, Child JS, Schwaiger M, Perloff JK, Schelbert HR. Left ventricular geometry and function in adults with Ebstein's anomaly of the tricuspid valve. Circulation. 1987;75:353-9.

10. Brown ML, Dearani JA, Danielson GK, Cetta F, Connolly HM, Warnes CA, et al. Effect of operation for Ebstein anomaly on left ventricular function. Am J Cardiol. 2008:102:1724-7.

11. Celermajer DS, Dodd SM, Greenwald SE, Wyse RK, Deanfield JE. Morbid anatomy in neonates with Ebstein's anomaly of the tricuspid valve: pathophysiologic and clinical implications. J Am Coll Cardiol. 1992;19: 1049-53.

12. Lee AH, Moore IE, Fagg NL, Cook AC, Kakadekar AP, Allan LD, et al. Histological changes in the left and right ventricle in hearts with Ebstein's malformation and tricuspid valvar dysplasia: a morphometric study of patients dying in the fetal and perinatal periods. Cardiovasc Pathol. 1995:4:19-24.

13. Moon JC, Messroghli DR, Kellman P, Piechnik SK, Robson MD, Ugander M, et al. Myocardial T1 mapping and extracellular volume quantification: a Society for Cardiovascular Magnetic Resonance (SCMR) and CMR working Group of the European Society of cardiology consensus statement. J Cardiovasc Magn Reson. 2013:15:92.

14. aus dem Siepen F, Buss SJ, Messroghli D, Andre F, Lossnitzer D, Seitz S, et al. T1 mapping in dilated cardiomyopathy with cardiac magnetic resonance: quantification of diffuse myocardial fibrosis and comparison with endomyocardial biopsy. Eur Heart J Cardiovasc Imaging. 2015;16:210-6.

15. Beek AM, Bondarenko O, Afsharzada F, van Rossum AC. Quantification of late gadolinium enhanced CMR in viability assessment in chronic ischemic heart disease: a comparison to functional outcome. J Cardiovasc Magn Reson 2009:11:6.

16. Masci PG, Schuurman R, Andrea B, Ripoli A, Coceani M, Chiappino S, et al. Myocardial fibrosis as a key determinant of left ventricular remodeling in idiopathic dilated cardiomyopathy: a contrast-enhanced cardiovascular magnetic study. Circ Cardiovasc Imaging. 2013;6:790-9.

17. Weng Z, Yao J, Chan RH, He J, Yang X, Zhou Y, et al. Prognostic value of LGE-CMR in HCM: a meta-analysis. JACC Cardiovasc Imaging. 2016;9: 1392-402.

18. Fontana M, Pica S, Reant P, Abdel-Gadir A, Treibel TA, Banypersad SM, et al Prognostic value of late gadolinium enhancement cardiovascular magnetic resonance in cardiac amyloidosis. Circulation. 2015;132:1570-9.

19. Babu-Narayan SV, Kilner PJ, Li W, Moon JC, Goktekin O, Davlouros PA, et al. Ventricular fibrosis suggested by cardiovascular magnetic resonance in adults with repaired tetralogy of fallot and its relationship to adverse markers of clinical outcome. Circulation. 2006;113:405-13.
20. Broberg CS, Huang J, Hogberg I, McLarry J, Woods P, Burchill LJ, et al. Diffuse LV myocardial fibrosis and its clinical associations in adults with repaired tetralogy of Fallot. JACC Cardiovasc Imaging. 2016;9:86-7.

21. Kozak MF, Redington A, Yoo SJ, Seed M, Greiser A, Grosse-Wortmann L. Diffuse myocardial fibrosis following tetralogy of Fallot repair: a T1 mapping cardiac magnetic resonance study. Pediatr Radiol. 2014;44:403-9.

22. Carpentier A, Chauvaud S, Mace L, Relland J, Mihaileanu S, Marino JP, et al. A new reconstructive operation for Ebstein's anomaly of the tricuspid valve. J Thorac Cardiovasc Surg. 1988;96:92-101.

23. Fratz S, Chung T, Greil GF, Samyn MM, Taylor AM, Valsangiacomo Buechel ER, et al. Guidelines and protocols for cardiovascular magnetic resonance in children and adults with congenital heart disease: SCMR expert consensus group on congenital heart disease. J Cardiovasc Magn Reson. 2013;15:51.

24. Alfakih K, Reid S, Jones T, Sivananthan M. Assessment of ventricular function and mass by cardiac magnetic resonance imaging. Eur Radiol. 2004;14: 1813-22.

25. Yalonetsky S, Tobler D, Greutmann M, Crean AM, Wintersperger BJ, Nguyen $\mathrm{ET}$, et al. Cardiac magnetic resonance imaging and the assessment of ebstein anomaly in adults. Am J Cardiol. 2011;107:767-73.

26. White SK, Sado DM, Fontana M, Banypersad SM, Maestrini V, Flett AS, et al. T1 mapping for myocardial extracellular volume measurement by CMR: bolus only versus primed infusion technique. JACC Cardiovasc Imaging. 2013;6:955-62.

27. Hosch O, Sohns JM, Nguyen TT, Lauerer P, Rosenberg C, Kowallick JT, et al. The total right/left-volume index: a new and simplified cardiac magnetic resonance measure to evaluate the severity of Ebstein anomaly of the tricuspid valve: a comparison with heart failure markers from various modalities. Circ Cardiovasc Imaging. 2014;7:601-9.

28. Josta CHA, Connolly HM, Edwards WD, Carole DH, Warnes A, Danielson GK. Ebstein's anomaly - review of a multifaceted congenital cardiac condition. Swiss Med Wkly. 2005;165:269-81.

29. Attie F, Rosas M, Rijlaarsdam M, Buendia A, Zabal C, Kuri J, et al. The adult patient with Ebstein anomaly. Outcome in 72 unoperated patients. Medicine (Baltimore). 2000;79:27-36.

30. de Vette LC, Brugts JJ, McGhie JS, Roos-Hesselink JW. Long-lasting symptoms and diagnostics in a patient with unrecognized right sided heart failure: why listening to the heart is so important. World J Cardiol 2014;6:345-348.

31. Segura AM, Frazier OH, Buja LM. Fibrosis and heart failure. Heart Fail Rev. 2014;19:173-85.

32. Chauvaud S, Berrebi A, d'Attellis N, Mousseaux E, Hernigou A, Carpentier A. Ebstein's anomaly: repair based on functional analysis. Eur J Cardiothorac Surg. 2003;23:525-31.

33. Andrew HS, Lee M, Isabella E, Moore D, Nuala LK, Fagg M. histologic changes in the left and right ventrice in hearts withEebstein's malformation and tricuspid valvar dysplasia : a morphometric study of patients dying dying in the fatal and perinatal periods. Cardiovasc Pathol. 1995:4:19-24.

34. Frescura C, Angelini A, Daliento L, Thiene G. Morphological aspects of Ebstein's anomaly in adults. Thorac Cardiovasc Surg. 2000;48:203-8.

35. Buturak A, Saygili O, Ulus S, Kalfa M, Karabulut H, Alhan C, et al. Right ventricular endomyocardial fibrosis mimicking Ebstein anomaly in a patient with Behcet's disease: case report and review of the literature. Mod Rheumatol. 2014:24:532-6.

36. Balakrishnan KG, Sapru RP, Sasidharan K, Venkitachalam CG. A comparison of the clinical, haemodynamic and angiographic features in right ventricular endomyocardial fibrosis and Ebstein's anomaly of the tricuspid valve. Cardiology. 1982;69:265-75.

37. Handa S, Fujii I, Ohonishi S, Yamazaki H, Nakamura Y. Strategy to manage pump failure due to chronic pulmonary diseases--pathophysiology and treatment of right ventricular overload. Jpn Circ J. 1986;50:350-8.

38. Chadwick RS, Azancot-Benisty A, Ohayon J, Ito Y. Right and left ventricle interaction and remodeling in congenital heart disease. Adv Exp Med Biol. 1993;346:373-81.

39. Hong YJ, Park CH, Kim YJ, Hur J, Lee HJ, Hong SR, et al. Extracellular volume fraction in dilated cardiomyopathy patients without obvious late gadolinium enhancement: comparison with healthy control subjects. Int J Cardiovasc Imaging. 2015;31(Suppl 1):115-22.

40. Attenhofer Jost $\mathrm{CH}$, Connolly HM, Scott CG, Burkhart HM, Warnes CA Dearani JA. Outcome of cardiac surgery in patients 50 years of age or older with Ebstein anomaly: survival and functional improvement. J Am Coll Cardiol. 2012;59:2101-6. 
41. Arya P, Beroukhim R. Ebstein anomaly: assessment, management, and timing of intervention. Curr Treat Options Cardiovasc Med. 2014;16:338.

42. Dusenbery SM, Jerosch-Herold M, Rickers C, Colan SD, Geva T, Newburger JW, et al. Myocardial extracellular remodeling is associated with ventricular diastolic dysfunction in children and young adults with congenital aortic stenosis. J Am Coll Cardiol. 2014;63:1778-85.

Ready to submit your research? Choose BMC and benefit from:

- fast, convenient online submission

- thorough peer review by experienced researchers in your field

- rapid publication on acceptance

- support for research data, including large and complex data types

- gold Open Access which fosters wider collaboration and increased citations

- maximum visibility for your research: over $100 \mathrm{M}$ website views per year

At $\mathrm{BMC}$, research is always in progress.

Learn more biomedcentral.com/submissions 